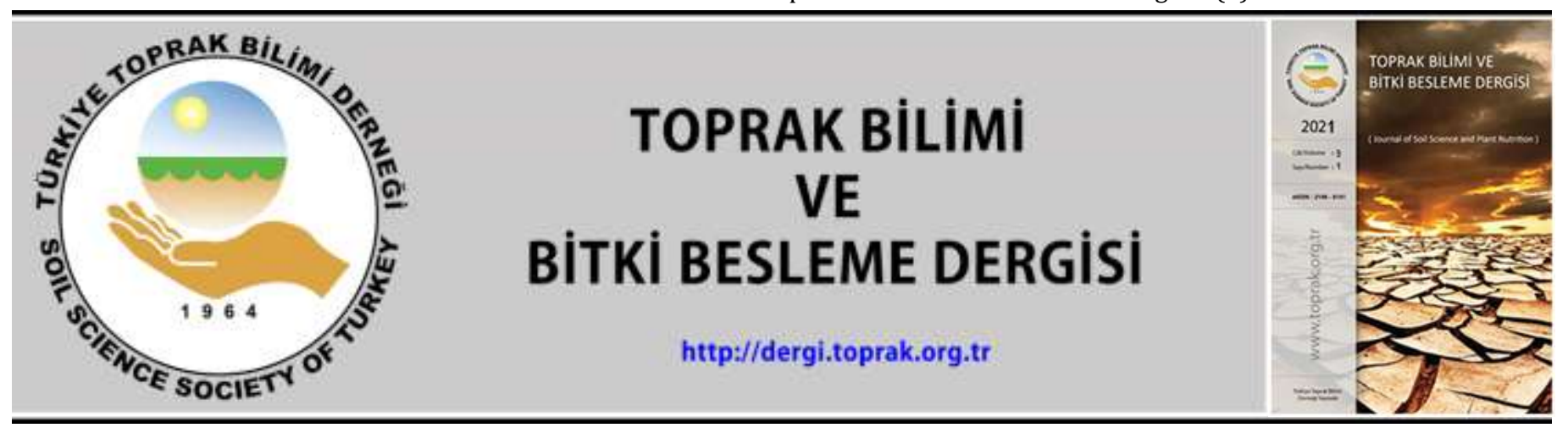

\title{
Sarımsak hasatıyla meydana gelen toprak kaybının belirlenmesi: Balıkesir-Altıeylül İlçesi örneği
}

\author{
(DMehmet Parlak*, (DTimuçin Everest
}

Çanakkale Onsekiz Mart Üniversitesi Lapseki Meslek Yüksek Okulu, Lapseki-Çanakkale

\section{Özet}

Toprak erozyonu toprak degredasyonuna neden olan tehditlerden birisidir. Toprak erozyonunun toprak koşullarını, bitki verimini, biyoçeşitliliği ve insan beslenmesini tehdit ettiği bilinmektedir. Toprak kaynaklarının sürdürülebilirliğini şeker pancarı, patates, havuç, sarımsak gibi bitkilerin hasatı sırasında oluşan toprak kayıpları etkilemektedir. Bu araştırmanın amacı sarımsak hasatıyla meydana gelen toprak kaybını, kaybı etkileyen faktörleri, kaybolan topraktaki besin maddelerinin miktarını ve maliyetini belirlemektir. Sarımsak hasadı yılda 3.23 ton ha-1 toprak kaybına yol açmaktadır. Sarımsak hasatında toprak kaybındaki değişkenliğin \%95'i toprağın nem içeriği, toprak bünyesi, hacim ağırlığı, kireç, organik madde, bitki sıklığı, baş ağırlığı ve sarımsak

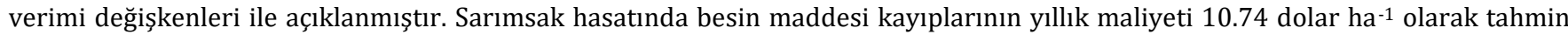
edilmiștir. Araștırma sonucu, sarımsak hasatıyla meydana gelen toprak kaybı toplam toprak erozyonunun belirlenmesinde dikkate alınmalıdır.

Anahtar Kelimeler: Toprak kaybı, sarımsak, besin madde kayıpları, hasat erozyonu, su kirliliği

\section{Soil losses due to garlic harvesting: A case study Balıkesir-Altıeylül Town}

\begin{abstract}
Soil erosion generates a threat of soil degradation. Soil erosion exerts threats also on soil conditions, crop yield, biodiversity and human nutrition. Sustainability of soil resources is influenced by soil loss through harvesting of sugar beet, potato, carrot and garliclike plants. This study was conducted to determine soil loss through garlic harvesting, factors effecting soil loss, quantity and cost of nutrients lost through soil loss. Mean annual soil loss was 3.23 tonnes ha-1 harvest ${ }^{-1}$ for garlic. $95 \%$ of variation in soil loss due to garlic harvesting was explained by gravimetric water content, soil texture, bulk density, lime, organic matter, plant density and

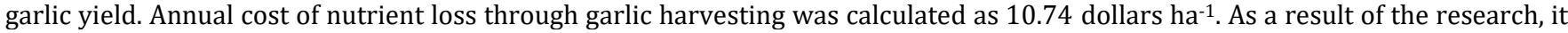
was suggested that soil loss caused by garlic harvest should be taken into account in determining total soil erosion.
\end{abstract}

Keywords: Soil loss, garlic, nutrient losses, harvest erosion, water pollution

(C) 2021 Türkiye Toprak Bilimi Derneği. Her Hakkı Saklıdır

\section{Giriş}

Toprak, bitkiler için su ve besin maddeleri sağlamakta, suyu depolamakta ve filtrelemektedir. Hammadde temini, karbon havuzu, kültürel ortam görevi görmektedir. Aynı zamanda toprak, gezegendeki genetik çeşitliliğin en büyük bölümünü barındırmaktadır (Field ve ark., 2017). Artan ve yoğunlaşan tarımsal üretim nedeniyle dünyanın birçok bölgesinde toprak kullanım sınırlarına ulaşmış ve bu da toprak degredasyonuyla birlikte tarım arazilerinin nihai kaybına neden olmuştur (Lal, 2009). Toprak degredasyonu, topraktaki besin maddelerinin kaybına ve ürün veriminde düșmeye ve yetersiz beslenmeye yol açarak hızla büyüyen nüfus için mevcut gıdanın hem kalitesini hem de miktarını azaltabilir (Pozza ve Field, 2020).

Toprak degredasyonuna neden olan etmenlerden birisi de toprak erozyonudur. Küresel toprak degredasyonunun önemli bir bileșeni de hasat erozyonudur. Șeker pancarı (Beta vulgaris L.), havuç (Daucus carota L.), kereviz (Apium groveolens L.), turp (Raphanus sativus L.), patates (Solanum tuberosum L.), soğan (Allium cepa L.), yer fistığı (Arachis hypogaea L.), pırasa (Allium porrum L.) ve sarımsak (Allium sativum L.) gibi bitkiler hasat edildiklerinde bu bitkilere yapışmış olan topraklar bulundukları alandan başka alanlara

\section{* Sorumlu yazar:}

Tel. : $02865226104 \quad$ Geliş Tarihi

E-posta : mehmetparlak06@hotmail.com Kabul Tarihi
30 Ocak 2021

14 Nisan 2021
e-ISSN : $2146-8141$

DOI : $10.33409 /$ tbbbd.871070 
taşınırlar. Bu sürece bitki hasadı nedeniyle toprak kaybı (BHTK) (soil loss due to crop harvesting (SLCH)) veya hasat erozyonu denilmektedir (Poesen ve ark., 2001; Oztas ve ark., 2002; Panagos ve ark., 2019). Diğer erozyon çeşitlerine (su, rüzgar ve toprak işleme erozyonu) göre hasat erozyonu daha az dikkat çekmesine rağmen (Parlak ve ark., 2008; Oshunsanya ve ark., 2018; Oshunsanya ve ark., 2019; Parlak, 2019) toprak erozyonunun saptanmasında gözönünde bulundurulmalıdır.

Sarımsak yemeklere tat ve lezzet verdiği için mutfakların vazgeçilmez sebzelerinden birisidir. 2017 yılında dünyada üretilen sarımsağın (28 164054 ton) \%78.80'i Çin'de gerçekleşmiştir. Çin' i Hindistan, Bangladeş, Güney Kore ve İspanya izlemektedir. Türkiye’ nin sarımsak üreten ülkeler arasındaki sıralaması 13. olarak gerçekleşmiştir (FAO, 2017). 2018 yılında Türkiye' de üretilen 116840 ton kuru sarımsağın 4242 tonu (\%3.63'ü) Balıkesir'de üretilmiştir (TÜİK, 2021). Türkiye İstatistik Kurumu (TÜİK) verileri incelendiğinde Türkiye'de sarımsak tarımı yapılan toprakların \% 5.64'ü (7140 da) Balıkesir ilinde bulunmaktadır (TÜIIK, 2021). Balıkesir ili sarımsak tarımında Türkiye genelinde altıncı sırada olup aynı zamanda Marmara Bölgesi'nde en fazla üretimin yapıldığı ildir. Bu nedenle sarımsak tarımı yapılan toprakların sürdürülebilir kullanılması, mevcut durumlarının ortaya konması önem arz etmektedir. Yapılan literatür incelemesinde Türkiye'de tarlada parsel ölçeğinde sarımsak hasatıyla meydana gelen toprak kaybıyla ilgili yayınlanmış araştırmaya rastlanılmamıştır. Bu araştırma sarımsak hasatı sırasında toprak kayıplarını belirlemek, toprak kaybını etkileyen faktörleri ve hasatla kaybolan topraktaki besin maddelerinin miktarı ile maliyetini hesaplamak için yapılmıştır.

\section{Materyal ve Yöntem}

\section{Çalışma alanı}

Çalışma alanı Balıkesir ilinin Altıeylül sınırları içinde bulunmaktadır. Altıeylül ilçesi $39^{\circ} 41^{\prime \prime}-39^{\circ} 44^{\prime}$ kuzey enlemleri ile $27^{\circ} 51^{\prime}-27^{\circ} 52^{\prime}$ doğu boylamları arasında konumlanmaktadır (Şekil 1). Altıeylül ilçesinde yoğun olarak serin iklim tahılları [buğday (Triticum aestivum L.), arpa (Hordeum vulgare L.), çavdar (Secale cereale L.) ve yulaf (Avena sativa L.)], mısır (Zea mays L.), fiğ (Vicia sativa L.), yonca (Medicago sativa L.) ve sarımsak yetiştirilmektedir. Balıkesir meteoroloji istasyonundan elden edilen 40 yıllık iklimsel verilere göre yıllık ortalama sıcaklık ve yağış sırasıyla $14.7^{\circ} \mathrm{C}$ ve $524.2 \mathrm{~mm}$ 'dir (MGM, 2021). Araştırma Balıkesir'in Altıeylül İlçesinde en çok sarımsak üretimi yapılan 2 köyde (Pamukçu köyü ve Cinge köyü) yapılmıştır. Sarımsak dişlerinin dikimi 2017 yılının Ekim ayında gerçekleştirilmiştir. Çift sıralı yapılan dikimlerde 120 $150 \mathrm{~cm}$ genişliğine sahip olan tahtalar kullanılarak $10 \mathrm{~cm}$ 'ye $10 \mathrm{~cm}$ mesafe ile sıra arası ve sıra üzeri mesafe ayarlanmış ve 12 ila 15 sıralı dikim gerçekleştirilmiştir. Gübreleme işlemi için Şubat ayında $25 \mathrm{~kg} / \mathrm{da}$ üre (\%46N) ve Mart ayında $20 \mathrm{~kg} / \mathrm{da}$ triple süper fosfat (\%43) uygulaması yapılmıştır. Sarımsak bölgede kışlık olarak yetiştirildiği için yağışlar genellikle yeterli durumdadır. Yetersiz yağış durumunda ise sulama işlemi yapılmaktadır. Çalışmanın gerçekleştirildiği arazilerde ekim işleminden sonra bir sulama yapılarak çimlenme teşvik edilmiştir. Son sulama ise hasadı kolaylaştımak için Nisan ayının son haftasından başlamak üzere beşer gün aralıklar ile dört sulama olacak şeklinde planlanarak gerçekleştirilmiştir. Sarımsak arazilerinde yabancı ot mücadelesini sağlamak, havalandırmayı artırmak ve bitki gelişimi desteklemek için çapalama önemli bir kültürel işlemdir. Sarımsak arazilerinde iki kez çapalama yapılmıştır. Bunlardan birincisi bitkilerin ilk çıkışını takiben ikincisi ise Nisan ayında yapılmıştır. Sarımsağın önemli bir zararlısı olan tel kurdu (Agriotes spp.) ile kimyasal mücadele için dekara $1.2 \mathrm{~kg}$, \%25'lik Chlorpyrifos-ethyl etken maddeli zirai mücadele ilacı kullanılmıştır. Hasat 2018 yılı Mayıs ayının ortasında gerçekleştirlmiştir.

\section{Örnekleme metodu}

Pamukçu ve Cinge köylerindeki sarımsak tarlaları küçük büyüklükte ( 5 ile 8 da arasında) ve hasat işlemi maliyetli olduğu için sarımsakta hasat Mayıs 2018'te elle (Şekil 2 A-D) yapılmıştır. Sarımsakta hasat yapılmadan 5 gün önce toprak ve bitkinin kolayca ayrılması için yağmurlama sulama yapılmıştır. Hasat öncesi sarımsak tarlalarının sulanması yaygın bir uygulamadır. Sarımsakta 18 örnekleme (2 köy x 3 sarımsak tarlası x 3 parsel= 18) yapılmıștır. Parsel büyüklüğü $2 \mathrm{mx} 2 \mathrm{~m}=4 \mathrm{~m}^{2}$ dir. Bitki sıklığı(baş ha-1) her parseldeki sarımsak sayısından saptanmıștır. Sarımsak parsellerindeki tüm bitkiler hasat edilmiștir. Hasat edilen parseldeki sarımsaklardan rastgele 14-26 baş seçilmiştir. Rastgele seçilen sarımsak başları ile bu başların üzerine yapışmış topraklar tartılmış, daha sonra başların üzerindeki topraklar sıyrılmış ve bir kovanın içinde sarımsak başları yıkanmıştır. Yıkanan sarımsak başları daha sonra tartılmıştır. Sarımsak verimi $\left(\mathrm{M}_{\mathrm{cy}}\right)$ (ton ha-1) baş ağırlığı ve bitki sıklığından hesaplanmıștır. 


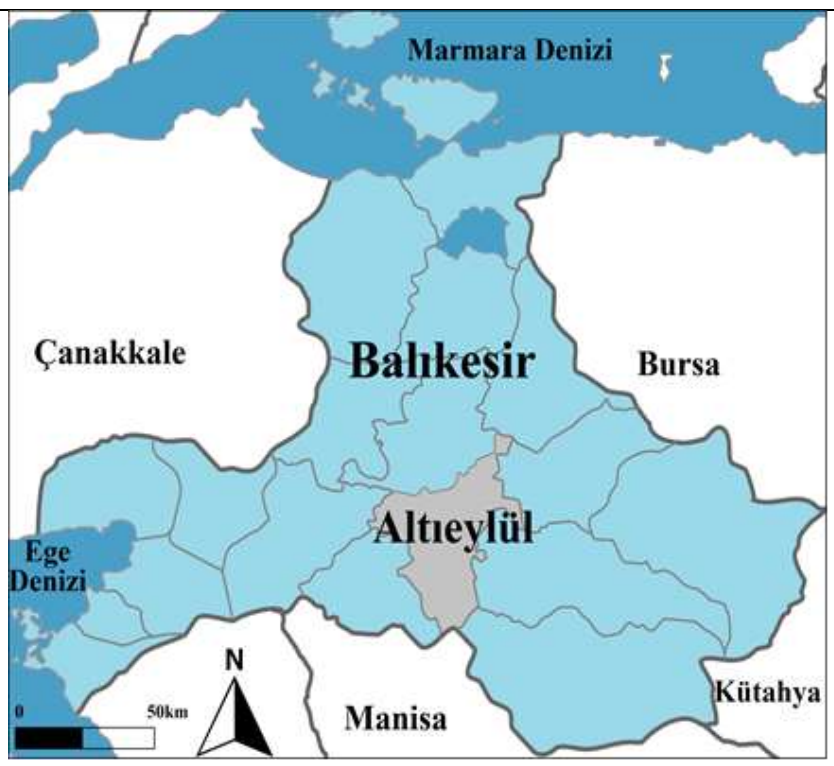

Şekil 1. Çalışma alanının konumu
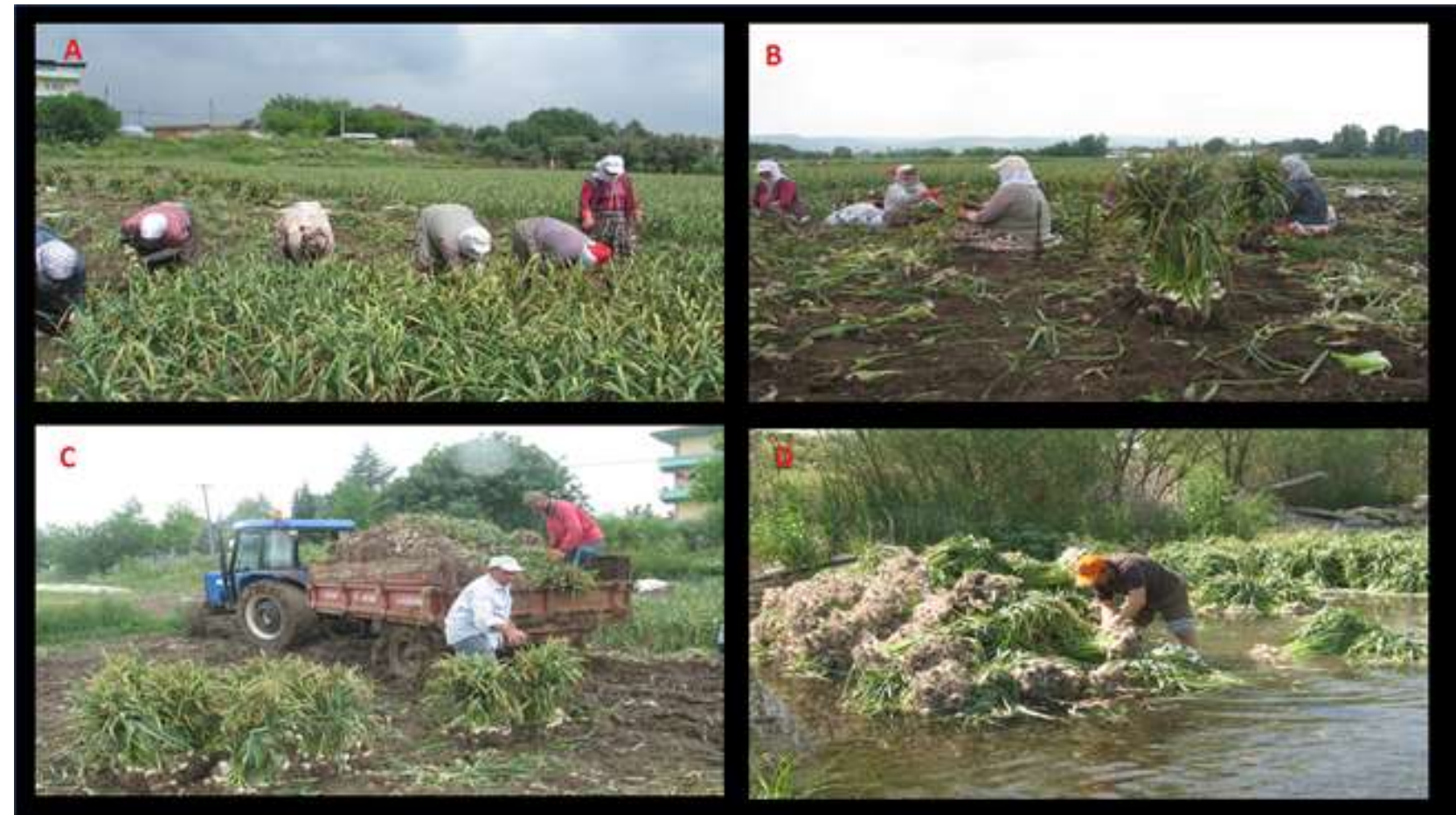

Şekil 2. Elle sarımsak hasatı (A), sarımsağın demet şeklinde bağlanması (B), sarımsağın römorka yüklenmesi (C), sarımsağın derede yıkanması (D).

\section{Toprak kaybı ve besin maddesi kaybının belirlenmesi}

Bitki hasadıyla toprak kaybı (BHTK) birim bitki ağırlı̆̆ındaki fırın kuru toprağı veya birim alandaki fırın

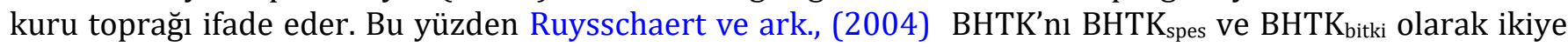
ayırmıştır.

$$
\text { BHTK }_{\text {spes }}\left(\mathrm{kg} \mathrm{kg}^{-1}\right)=\frac{M d s+M r f}{M b i t k i}
$$

Burada $\mathrm{M}_{\mathrm{ds}}=$ fırın kuru toprağın ağırlığı $(\mathrm{kg}), \mathrm{M}_{\mathrm{rf}}=$ kaya parçacıklarının kütlesi $(\mathrm{kg})$ ve $\mathrm{M}_{\text {bitki }}=$ net bitki ağırlığı (kg) (temizlenmiş sarımsak başlarının ağırlığı),

$$
\mathrm{BHTK}_{\text {spes } / \mathrm{p}}\left(\mathrm{g} \text { baş-1) }=\frac{M d s+M r f}{N p l}\right.
$$

Burada $\mathrm{N}_{\mathrm{pl}}=1 \mathrm{~m}^{2}$ deki sarımsak başlarının sayısı. 
Burada $\mathrm{M}_{\mathrm{cy}}=$ sarımsak verimi (ton ha-1 hasat $^{-1}$ ).

Besin maddesi kaybı (kg ha-1 hasat-1 $)=$ Besin maddesi içeriği $\left(\mathrm{g} \mathrm{kg}^{-1}\right.$ toprak) x BHTK bitki $\left(\right.$ ton ha $^{-1}$ hasat $\left.^{-1}\right)$

\section{Toprak analizleri}

Toprakların bazı fiziksel ve kimyasal özelliklerini saptamak için toprak örnekleri $0-20 \mathrm{~cm}$ derinlikten paslanmaz çelik kürekle ve çelik silindirlerle alınmıştır. Hasat sırasında alınmış toprak örneklerinin nem kapsamları gravimetrik olarak hesaplanmıștır (Topp ve Ferre, 2002). Daha sonra toprak örnekleri laboratuvara getirilerek kurutulduktan sonra $2 \mathrm{~mm}$ ' lik elekten elenerek analizlere hazır hale getirilmiștir.

Toprak örneklerinde bünye analizi hidrometre metoduna göre yapılarak kum, silt ve kil miktarları belirlenmiştir (Gee ve Or, 2002). Hacim ağırlığı bozulmamış örnek alma kapları yardımıyla yapılmıștır (Grossman ve Reinsch, 2002). Kireç Scheibler kalsimetresi ile hacimsel olarak tayin edilmiştir (Loeppert ve Suarez,1996). Organik madde yaş yakma yöntemine göre belirlenmiştir (Nelson ve Sommers, 1996). Toplam azot (N) Kjeldahl yöntemine göre yapılmıştır (Bremner, 1996). Alınabilir fosfor (P) 0.5 M sodyum bikarbonat $(\mathrm{pH}=8.5)$ ile ekstrakte edilmiş, askorbik asitte renklendirilerek spektrofotometrede standart seri eşliğinde okunmuştur (Kuo, 1996). Alınabilir potasyum (K) pH'sı 7 olan $1 \mathrm{~N}$ amonyum asetat kullanılarak ekstrakte geçen potasyum miktarının alev fotometrede okunmasıyla belirlenmiştir (Helmke ve Sparks, 1996).

\section{Gübre gereksinmesinin belirlenmesi}

Sarımsak hasadıyla kaybolan topraklardaki besin maddelerinin maliyetini belirlemek için toprak analiz sonuçlarına göre üre, triple süperfosfat (TSP) ve potasyum sülfat $\left(\mathrm{K}_{2} \mathrm{SO}_{4}\right)$ miktarları 5., 6. ve 7. eşitlikler yardımıyla hesaplanmıştır.

$$
\begin{aligned}
& \text { Üre }(\mathrm{kg})=100 \times \text { Uzaklaşan } \mathrm{N}(\mathrm{kg} \text { ha- } 1 \text { hasat- } 1) / 46 \\
& \text { Triple superfosfat }(\mathrm{kg})=100 \times \text { Uzaklaşan } \mathrm{P}_{2} \mathrm{O}_{5}(\mathrm{~kg} \text { ha- } 1 \text { hasat- } 1) / 43 \\
& \text { Potasyum sülfat }(\mathrm{kg})=100 \times \text { Uzaklaşan } \mathrm{K}_{2} \mathrm{O}(\mathrm{kg} \text { ha- } 1 \text { hasat- } 1) / 50
\end{aligned}
$$

Eşitliklerde 46, 43 ve 50 üre, triple süperfosfat ve potasyum sülfat gübrelerindeki $\mathrm{N}_{,} \mathrm{P}_{2} \mathrm{O}_{5}$ ve $\mathrm{K}_{2} \mathrm{O}$ yüzdelerini göstermektedir.

\section{İstatistiksel değerlendirme}

Korelasyon katsayıları ve çoklu regresyon eşitlikleri SAS istatistik programı kullanılarak (SAS Institute Inc.,1999) belirlenmiştir. Spearman korelasyon katsayıları kullanılmıştır. Regresyon analizlerinde bağımlı değişken $\mathrm{BHTK}_{\text {spes/p; }}$ tahminleyici olarak kullanılmış değişkenler ise toprak nemi, kil, silt, ince kum, kaba kum, hacim ağırlığı, organik madde, kireç, bitki sıklığı, baş ağırlığı ve sarımsak verimidir.

\section{Bulgular ve Tartışma}

\section{Sarımsak hasatının neden olduğu toprak kaybı}

BHTK $_{\text {spes, }} \mathrm{BHTK}_{\text {spes/p }}$, BHTK organik madde, bitki sıklığı, baş ağırlığı ve sarımsak verimi Çizelge 1'de verilmiştir. Sarımsak hasatındaki

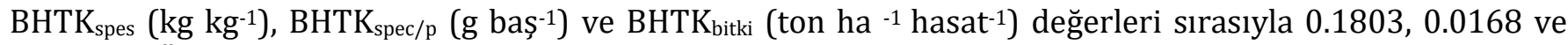
3.23 dür. Örnekleme yapılan toprakların bünyesi kil ve kumlu killi tın olarak belirlenmiştir. Toprakların hacim ağırlığı $1.16 \mathrm{~g} \mathrm{~cm}^{-3}$, kireç içeriği \%17.01, organik madde ise \%2.29 olarak saptanmştır. Sarımsak yetiştirilen toprakların ana materyali kireçtaşı olduğundan kireç kapsamları genellikle yüksek çımıştır. Bitki sıklığı (baş ha- ${ }^{-1}$ ), baş ağırlı̆̆ (g) ve sarımsak verimi(ton ha-1 hasat $^{-1}$ ) sırasıyla 188 333, 97.23 ve 17.58 olarak belirlenmiștir.

\section{Sarımsak hasatındaki toprak kaybıyla toprak ve bitki özellikleri arasındaki ilişkiler}

Elle sarımsak hasatında tüm değişkenler arasındaki korelasyon katsayıları Çizelge 2'de verilmiştir. BHTK spes toprak nem içeriğiyle önemli ölçüde korelasyon gösterirken $\mathrm{BHTK}_{\text {spes } / \mathrm{p}} \mathrm{CaCO}_{3}$ ile önemli düzeyde korelasyon göstermiştir. $\mathrm{BHTK}_{\text {spes }}$ toprak nemi arttıkça artmış, $\mathrm{BHTK}_{\text {spes/p }}$ ise $\mathrm{CaCO}_{3}$ azaldıkça artmıştır. $\mathrm{BHTK}_{\text {bitki hasat }}$ sırasındaki toprak nem kapsamı, $\mathrm{CaCO}_{3}$ ve sarımsak verimiyle önemli olarak korelasyonlu bulunmuştur. BHTK $_{\text {bitki }}$ toprak nemi ve sarımsak verminin artmasıyla artmış, $\mathrm{CaCO}_{3}$ un artmasıyla azalmıştır. 


\begin{tabular}{|c|c|}
\hline Ölçülen değişken & Elle hasat değerleri* \\
\hline BHTK $_{\text {spes }}\left(\mathrm{kg} \mathrm{kg}^{-1}\right)$ & $0.1803 \pm 0.1126$ \\
\hline $\mathrm{BHTK}_{\text {spes } / \mathrm{p}}\left(\mathrm{g}\right.$ başs $\left.{ }^{-1}\right)$ & $0.0168 \pm 0.0111$ \\
\hline BHTK $_{\text {bitki }}\left(\right.$ ton ha ${ }^{-1}$ hasat $^{-1}$ ) & $3.23 \pm 2.12$ \\
\hline Hasat sırasında toprak nem içeriği (\%) & $36.85 \pm 4.78$ \\
\hline İnce kum (\%) & $24.71 \pm 7.53$ \\
\hline Kaba kum (\%) & $12.12 \pm 1.76$ \\
\hline Kil (\%) & $45.63 \pm 8.93$ \\
\hline Silt $(\%)$ & $17.54 \pm 2.69$ \\
\hline Hacim ağırlığ $\left(\mathrm{g} \mathrm{cm}^{-3}\right)$ & $1.16 \pm 0.09$ \\
\hline $\mathrm{CaCO}_{3}(\%)$ & $17.01 \pm 8.19$ \\
\hline Organik madde (\%) & $2.29 \pm 0.49$ \\
\hline Bitki sıklığı (baş ha-1) & $188333 \pm 40475$ \\
\hline Baş ağırlığı (g) & $97.23 \pm 23.73$ \\
\hline Sarımsak verimi (ton ha ${ }^{-1}$ hasat $^{-1}$ ) & $17.58 \pm 3.89$ \\
\hline
\end{tabular}

* Ortalama, \pm standart sapma

Çizelge 2. Elle hasat edilen sarımsakta BHTK parametreleri ile toprak nem içeriği (W), toprak tekstürü, hacim ağırlı̆̆ı (HA), $\mathrm{CaCO}_{3}$, organik madde (OM), bitki sıklığı (BS), baş ağırlığı (BA) ve sarımsak verimi (M) arasındaki spearman korelasyon katsayıları*

\begin{tabular}{|c|c|c|c|c|c|c|c|c|c|c|c|c|c|}
\hline & $\mathrm{BHTK}_{\text {spes }}$ & $\mathrm{BHTK}_{\text {spes } / \mathrm{p}}$ & 3HTK ${ }_{\text {bitki }}$ & $\mathrm{W}$ & İ. kum & K. kum & Kil & Silt & HA & $\mathrm{CaCO}_{3}$ & $\mathrm{OM}$ & $\mathrm{BS}$ & $\mathrm{BA}$ \\
\hline $\mathrm{BHTK}_{\text {spes/p }}$ & $0.87^{*}$ & & & & & & & & & & & & \\
\hline BHTKbitki & $0.93^{*}$ & $0.92^{*}$ & & & & & & & & & & & \\
\hline W & $0.59 *$ & $0.53^{*}$ & $0.64^{*}$ & & & & & & & & & & \\
\hline İnce kum & -0.27 & -0.15 & -0.38 & -0.25 & & & & & & & & & \\
\hline Kaba kum & -0.12 & -0.15 & -0.13 & -0.19 & -0.23 & & & & & & & & \\
\hline Kil & 0.23 & 0.09 & 0.34 & 0.26 & $-0.97 *$ & 0.11 & & & & & & & \\
\hline Silt & 0.06 & 0.22 & 0.04 & -0.06 & $0.55^{*}$ & -0.39 & $-0.69 *$ & & & & & & \\
\hline $\mathrm{HA}$ & $-0.34^{*}$ & -0.24 & -0.42 & -0.23 & $0.62^{*}$ & 0.18 & $-0.56^{*}$ & 0.01 & & & & & \\
\hline $\mathrm{CaCO}_{3}$ & $-0.69^{*}$ & $-0.68^{*}$ & $-0.77^{*}$ & -0.34 & $0.49 *$ & -0.12 & -0.41 & 0.08 & 0.31 & & & & \\
\hline $\mathrm{OM}$ & -0.31 & -0.27 & -0.31 & -0.43 & 0.04 & -0.37 & 0.04 & 0.02 & -0.06 & 0.26 & & & \\
\hline BS & 0.26 & -0.03 & 0.31 & 0.43 & $-0.56^{*}$ & 0.15 & $0.51^{*}$ & -0.21 & $-0.50 *$ & -0.32 & -0.21 & & \\
\hline $\mathrm{BA}$ & 0.05 & $0.48^{*}$ & 0.26 & 0.01 & 0.04 & -0.27 & -0.06 & 0.27 & 0.03 & -0.21 & 0.17 & $-0.55^{*}$ & \\
\hline M & 0.16 & 0.39 & $0.48^{*}$ & 0.43 & -0.46 & -0.05 & 0.39 & -0.37 & -0.37 & $-0.47^{*}$ & -0.14 & 0.34 & $0.56^{*}$ \\
\hline
\end{tabular}

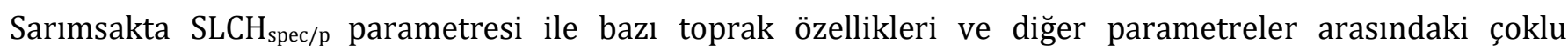
regresyon eşitlikleri Çizelge 3'de verilmiştir. Sarımsağın elle hasatındaki toprak kaybını tahmin etmek için en önemli değişkenler; hasat zamanında toprağın nem kapsamı, toprak bünyesi, hacim ağırlı̆̆ı, kireç, organik madde, bitki sıklığı, baş ağırlı̆̆ı ve sarımsak verimi olarak belirlenmiştir. Parlak ve ark., (2018) kereviz hasatında toprak kaybındaki değişimin \%33' ünün ince kum, kil ve bitki sıklı̆̆ı ile; yine aynı bitkinin hasatında toprak kaybındaki değişimin \%23'ünün ise ince kum ve organik maddeyle açıklanabildiğini belirtmişlerdir. Bazı araştırmacılar toprak kaybının nem arttıkça arttığını (Li ve ark., 2006; Isabirye ve ark., 2007; Parlak ve Blanco-Canqui 2015; Dada ve ark., 2016; Parlak ve ark., 2016; Faraji ve ark., 2017), bazıları toprak kaybının kil veya silt arttıkça arttığını (Li ve ark., 2006; Dada ve ark., 2016; Oshunsanya 2016; Oshunsanya ve ark., 2019); kimi araştırmacılar toprak kaybının bitki sıklığı arttıkça arttı̆̆ını (Li ve ark., 2006; Oshunsanya 2016; Yu ve ark., 2016); bazı araştırmacılar ise toprak kaybının bitki verimi artıkça arttığını (Parlak ve ark., 2016; Oshunsanya ve ark., 2018) belirtmişlerdir. Fakat bazı araştırmacılar toprak kaybının kireç kapsamının artmasıyla azaldığını saptamışlardır (Ruysschaert ve ark., 2004; Parlak ve ark., 2016).

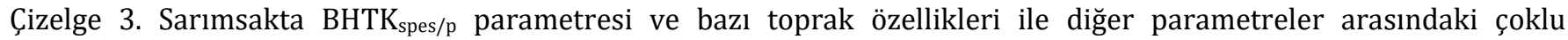
regresyon eșitlikleri $(\mathrm{n}=18)$

\begin{tabular}{|c|c|c|c|}
\hline No & Tahmini denklem & $\mathrm{R}^{2}$ & $\mathrm{p}$ \\
\hline 1 & $\begin{aligned} \mathrm{SLCH}_{\text {spes } / \mathrm{p}}(\mathrm{g} / \mathrm{baş})= & 8.3+0.00103(\text { Toprak nem içeriği })+0.084(\text { ince kum })-0.083(\mathrm{kaba} \text { kum })- \\
& 0.084(\text { kil })-0.084(\text { silt })-0.0298(\text { hacim ağırlığı })-0.000563\left(\mathrm{CaCO}_{3}\right)- \\
& 0.062(\text { organik madde })+0.0(\text { bitki sıklığı })+0.00116(\text { baş ağırlığ })- \\
& 0.00536(\text { sarımsak verimi) }\end{aligned}$ & 0.95 & 0.006 \\
\hline 2 & $\begin{aligned} \mathrm{SLCH}_{\text {spes } / \mathrm{p}}(\mathrm{g} / \mathrm{baş}= & -0.0208+0.00857(\text { Toprak nem içeriği })-0.000660\left(\mathrm{CaCO}_{3}\right)+0.000179(\mathrm{baş} \\
& \text { ağırlığ })\end{aligned}$ & 0.71 & 0.001 \\
\hline 3 & $\mathrm{SLCH}_{\text {spes} / \mathrm{p}}(\mathrm{g} / \mathrm{baș})=-0.0011+0.000789($ Toprak nem içeriği $)-0.000780\left(\mathrm{CaCO}_{3}\right)$ & 0.57 & 0.002 \\
\hline
\end{tabular}


Sarımsak hasatı için bulunan toprak kaybı (ton ha-1 hasat-1) Türkiye' deki havuç, İran'daki sarımsak, Türkiye'deki kerevizden daha düșük saptanmıșken; Çin'deki şeker pancarı, Uganda'daki tatlı patates (Ipomoea batatas), Nijerya' daki yam (Dioscorea spp.) ve kırmızı kokoyamdan (Xanthosoma sagittifolium) daha yüksek saptanmıştır (Çizelge 4). Saptadığımız toprak kaybı değeri; İran' daki sarımsaktan 1.94 kat daha düşükken, Çin' deki şeker pancarından 3.23 kat ve Nijerya' daki kırmızı kokoyamdan 215 kat daha yüksek saptanmıştır. Toprak kayıplarındaki bu farklılıkların nedeni toprak özellikleri, hasat zamanındaki yağış miktarı, toprak yönetimi ve bitki verimi olabilir. Berberoglu ve ark., (2020) PESERA (Pan European Soil Erosion Risk Assessment) modelini kullanarak Marmara Havzası' ndaki tarım alanlarında toprak erozyonunun 1.85 ton ha $^{-1}$ yll $^{-1}$ olduğunu bildirmişlerdir. Sarımsak hasatındaki erozyon değeri (3.23 ton ha-1 hasat $^{-1}$ ) Berberoglu ve ark., (2020)'nın bildirdiğinden 1.75 kat daha yüksek iken Schertz ve Nearing (2002)'in bildirdiği izin verilebilir toprak kayıp değerinden (11.2 ton ha-1 $\mathrm{yll}^{-1}$ ) 3.47 kat daha düşük bulunmuştur.

Çizelge 4. Elle hasat yapılan bitkilerde toprak kayıplarının karșılaștırılması (Ortalama \pm standart sapma)

\begin{tabular}{llll}
\hline Bitki & Ülke & Toprak kaybı (ton ha hasat $^{-1}$ ) & Kaynak \\
\hline Şeker pancarı & Çin & $1.00 \pm 0.60$ & Li ve ark., 2006 \\
Tatlı patates & Uganda & $0.09 \pm$ veri yok & Isabirye ve ark., 2007 \\
Yam & Nijerya & $3.21 \pm$ veri yok & Dada ve ark., 2016 \\
Kırmızı kokoyam & Nijerya & $0.015 \pm$ veri yok & Oshunsanya, 2016 \\
Havuç & Türkiye & $5.60 \pm$ veri yok & Parlak ve ark., 2016 \\
Sarımsak & İran & $6.27 \pm$ veri yok & Faraji ve ark., 2017 \\
Kereviz & Türkiye & $4.00 \pm 1.91$ & Parlak ve ark., 2018 \\
Sarımsak & Türkiye & $3.23 \pm 2.12$ & Bu araștırma \\
\hline
\end{tabular}

Sarımsak hasatıyla yılda 3.23 ton ha-1 toprak kaybolmaktadır. Kaybolan toprakla beraber profildeki toprağın derinliği de azalmaktadır. Yıllar boyunca hasat nedeniyle üst toprağın sürekli kaybı sarımsak tarımı yapılan alanlarda dikkat çekmeye başlayacaktır. Buna ilaveten sarımsak hasatıyla besin maddelerinin sürekli uzaklaşması tarım alanlarında besin maddelerinin azalmasına neden olabildiği gibi tarımın sürdürülebilirliğini etkilemektedir. Farklı araştırmacılar toprak profilindeki azalmayı bazı bitkiler için hesaplamışlardır. Poesen ve ark., (2001) radika ve şekerpancarında $0.33 \mathrm{~mm}$ yll ${ }^{-1}$; Parlak ve Blanco-Canqui, (2015) patateste $1.20 \mathrm{~mm} \mathrm{yll}^{-1}$; Faraji ve ark., (2017) beş bitkide (sarımsak, patates, şekerpancarı, turp ve kırmızı pancar) $0.30 \mathrm{~mm} \mathrm{yll}^{-1}$; Parlak ve ark., (2018) kerevizde $3.17 \mathrm{~mm}_{\text {yll }}{ }^{-1}$ olarak belirlemişlerdir. Araştırmamızda sarımsak hasatında toprak profilindeki azalma $0.31 \mathrm{~mm}$ yll ${ }^{-1}$ olarak hesaplanmıştır. Sarımsak hasatında toprak profilindeki azalma İran'da hasatı yapılan beş bitkideki(sarımsak, patates, şekerpancarı, turp ve kırmızı pancar) değerden yüksek, diğer araştırmacıların bulduklarından düşüktür. Stockman ve ark. (2014) küresel toprak oluşum hızını $0.11 \mathrm{~mm} \mathrm{yl}^{-1}$ olarak tahmin etmişlerdir. Sarımsak hasatında saptanılan değer $\left(0.31 \mathrm{~mm}_{\mathrm{yll}}{ }^{-1}\right)$ küresel toprak oluşum hızından yaklaşık 3 kat daha fazladır. Bu durum sarımsak yetiștirilen toprakların degradasyona uğradığını göstermektedir.

Hasattan sonra Pamukçu deresinde sarımsakların yıkanması suyun kirlenmesi ve sedimentasyon sorununa neden olabilmektedir. Derede besin maddelerinin birikimi siltasyon sorununun yanında sucul hayvanların habitatlarını olumsuz yönde etkileyebilmektedir. Bitkilerin hasat edilmesinin siltasyona neden olduğu başka araştırmacılar tarafından da belirtilmiştir (Li ve ark., 2006; Isabirye ve ark., 2007; Mwango ve ark., 2015; Oshunsanya 2016; Yu ve ark., 2016; Oshunsanya ve ark., 2019).

\section{Besin maddesi kayıplarının maliyeti}

Tarlalardan sarımsak hasatıyla kaybolan besin maddesi kayıplarının maliyeti Çizelge 5'te verilmiştir. Sarımsak hasatıyla kaybolan besin maddelerinin $\left(\mathrm{N}, \mathrm{P}_{2} \mathrm{O}_{5}\right.$ ve $\left.\mathrm{K}_{2} \mathrm{O}\right)$ yıllık maliyeti 10.74 dolar ha-1 olarak hesaplanmıştır. Farklı araştırmacılar hasat erozyonuyla kaybolan topraklardaki besin maddesi kayıplarının maliyetini hesaplamışlardır. Faraji ve ark., (2017) sarımsak hasatındaki yıllık maliyeti 8.61 dolar ha $^{-1}$; Parlak ve Blanco-Canqui (2015) patates hasatındaki yıllık maliyeti 2.92 dolar ha-1; Parlak ve ark., (2018) kereviz hasatındaki yıllık maliyeti 6.18 dolar ha-1; Parlak ve ark., (2020) rulo çim hasatındaki yıllık maliyetin ise 133.31 dolar ha-1 ile 444.26 dolar ha-1 $^{-1}$ arasında olduğunu saptamışlardır. 


\begin{tabular}{|c|c|c|c|c|c|}
\hline $\begin{array}{l}\text { Besin } \\
\text { elementi }\end{array}$ & $\begin{array}{l}\text { Ort. miktar } \pm \text { st. sapma } \\
\left(\mathrm{g} \mathrm{kg}^{-1}\right)\end{array}$ & $\begin{array}{l}\text { Kaybolan miktar } \\
\left(\mathrm{kg} \mathrm{ha}^{-1} \text { hasat }^{-1}\right)\end{array}$ & Gübre eşdeğeri & $\begin{array}{l}\text { Birim maliyeta } \\
\text { (dolar ton }^{-1} \text { ) }\end{array}$ & $\begin{array}{l}\text { Toplam maliyet } \\
\left(\text { dolar ha }^{-1} \text { hasat }^{-1}\right)\end{array}$ \\
\hline $\mathrm{N}$ & $1.172 \pm 2.562$ & 3.78 & $8.22 \mathrm{~kg}$ üre (\%46) & 362 & 2.97 \\
\hline $\mathrm{P}_{2} \mathrm{O}_{5}$ & $0.016 \pm 0.009$ & 0.12 & 0.28 kg TSP (\%43) & 435 & 0.12 \\
\hline \multirow[t]{2}{*}{$\mathrm{K}_{2} \mathrm{O}$} & $1.419 \pm 1.027$ & 4.58 & $9.16 \mathrm{~kg} \mathrm{KSO}_{4}(\% 50)$ & 836 & 7.65 \\
\hline & & & & Toplam & 10.74 \\
\hline
\end{tabular}

${ }^{a}$ Gübre fiyatları ticari satış değerine göre belirlenmiştir.

\section{Sonuç}

Hasat erozyonuyla ilgili araștırmalarda sarımsak az çalışılan bitki olmasına rağmen sarımsak hasatı yılda 3.23 ton ha-1 toprak kaybına neden olmaktadır. Sarımsağın elle hasatında toprak kaybını etkileyen faktörler; hasat sırasında toprağın nem kapsamı, toprak bünyesi, hacim ağırlığı, kireç, organik madde, baş ağırlığı ve sarımsak verimidir. Sarımsak hasatında kaybolan toprakla beraber $3.78 \mathrm{~kg} \mathrm{~N}^{-1}$ hasat $^{-1}, 0.12 \mathrm{~kg} \mathrm{P}_{2} \mathrm{O}_{5}$ ha $^{-1}$

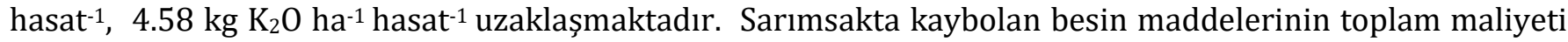
10.74 dolar ha-1 hasat-1 olarak saptanmıştır. Hasat erozyonunu azaltmak için sarımsak üreticileri hasat sırasındaki toprak nemine dikkat etmeli, bu konuda çiftçilere eğitim toplantıları düzenlenmelidir. Çiftçilerin bilincini arttırmak için ilgili kurumlar tarafından liflet, broşür gibi materyaller hazırlanarak üretici farkındalığını arttırmaya yönelik yayım çalışmaları yapılabilir. Şartlar elverirse sarımsak başlarının üzerindeki topraklar sıyrılmalı ve tarlalarda bırakılmalıdır. Hasat erozyonu toprakların sürdürülebilirliğini etkilediği için bu konuyla ilgili daha fazla araştırmalar yapılmalıdır. Hasat erozyonu ile ilgili yapılan çalışmaların karar verici ve politikacılar için mevcut mevzuatların güncellenmesinde fayda sağlayacağı umulmaktadır.

\section{Kaynaklar}

Berberoglu S, Cilek A, Kirkby M, Irvine B, Donmez C, 2020. Spatial and temporal evaluation of soil erosion in Turkey under climate change scenarios using the Pan European Soil Erosion Risk Assessment (PESERA) model. Environ. Monit. Assess. 192: 491.

Bremner JM, 1996. Nitrogen-Total. Methods of Soil Analysis. Part 3. Chemical Methods (ed. Sparks DL), American Society of Agronomy, Madison, Wisconsin, USA, pp. 1085-1122.

Dada P0O, Adeyanju OR, Adeosun OJ, Adewumi JK, 2016. Effects of soil physical properties on soil loss due to manual yam harvesting under a sandy loam environment. Int. Soil Water Conserv. Res. 4: 121-125.

FAO, 2017. FAOSTAT. Data.Crops.http://www.fao.org/faostat/en/\#data/QC (accessed 20 November 2019).

Faraji M, Chakan AA, Jafarizadeh M, Behbahani AM, 2017. Soil and nutrient losses due to root crops harvesting: a case study from south western Iran. Arch. Agron. Soil Sci. 63(11): 1523-1534.

Field D, Morgan CL, McBratney AB, 2017. Global Soil Security. Springer. 469 p.

Gee GW, Or D, 2002. Particle size analysis. Methods of Soil Analysis. Part 4, Physical Methods (ed. Dane JH, Topp GC), SSSA, Book Series No: 5, Madison, pp. 255-293.

Grossman RB, Reinsch TG, 2002. Bulk density and linear extensibility: core method. Methods of Soil Analysis. Part 4, Physical Methods (ed. Dane JH, Topp GC), SSSA, Book Series No: 5, Madison, pp. 201-293.

Helmke PA, Sparks DL, 1996. Lithium, sodium, potassium, rubidium, and calcium. Methods of Soil Analysis. Part 3.Chemical Methods (ed. Sparks DL), American Society of Agronomy, Madison, Wisconsin, USA, pp. 551-574.

Isabirye M, Ruysschaert G, Van Linden L, Poesen J, Magunda MK, Deckers J, 2007. Soil losses due to cassava and sweet potato harvesting: a case study from low input traditional agriculture. Soil Tillage Res. 92: 96-103.

Kuo S, 1996. Phosphorus. Methods of Soil Analysis. Part 3. Chemical Methods (ed. Sparks DL), American Society of Agronomy, Madison, Wisconsin, USA, pp. $869-920$.

Lal R, 2009. Soil degradation as a reason for inedequate human nutrition. Food Sec. 1(1): 45-57.

Li Y, Ruysschaert G, Poesen J, Zhang QW, Bai LY, Li L, Sun LF, 2006. Soil losses due to potato and sugar beet harvesting in NE China. Earth Surf. Proc. Land. 31: 1003-1016.

Mwango SB, Msanya BM, Mtakwa PW, Kimaro DN, Deckers J, Poesen J, Lilanga S, Sanga R, 2015. Soil loss due to crop harvesting in Usambara Mountains, Tanzania: the case of carrot, onion and potato. Int. J. Plant Soil Sci. 4(1): 1828.

Loeppert RH., Suarez DL, 1996. Carbonate and gypsum. Methods of Soil Analysis. Part 3. Chemical Methods (ed. Sparks DL), American Society of Agronomy, Madison, Wisconsin, USA, pp. 437-474.

MGM, 2021. Meteoroloji Genel Müdürlüğü, Balıkesir ili iklim verileri. (Erişim tarihi: 22 Mart 2021). https://www.mgm.gov.tr/veridegerlendirme/il-ve-ilceler-istatistik.aspx?k=H\&m=BALIKESIR 
Nelson DW, Sommers LE, 1996. Total carbon, organic carbon, and organic matter: Laboratory methods. Methods of Soil Analysis. Part 3. Chemical Methods (ed. Sparks DL), American Society of Agronomy, Madison, Wisconsin, USA, pp. 961-1010.

Oshunsanya SO, 2016. Quantification of soil loss due to white cocoyam (Colocasia esculentus) and red cocoyam (Xanthosoma sagittifolium) harvesting in traditional farming system. Catena 137: 134-143.

Oshunsanya SO, Yu H, Li Y, 2018. Soil loss due to root crop harvesting increases with tillage operations. Soil Tillage Res. 181: 93-101.

Oshunsanya SO, Yu H, Li Y, Saggar S, 2019. Root hairs and cortex contribute to soil due to root crop harvesting. Catena 174: 514-523.

Oztas T, Ozbek AK, Turan M, 2002. The cost of soil lost from fields due to removal on harvested sugar beet: a case study in Turkey. Soil Use Manage. 18: 236-237.

Panagos P, Borrelli P, Poesen J, 2019. Soil loss due to crop harvesting in the European Union: a first estimation of an underrated geomorphic process. Sci. Total Environ. 664: 487-498.

Parlak M, 2019. Greenhouse gas footprint of replacing nutrients lost through soil erosion due to root and tuber crops harvesting. Mediterranean Agric. Sci. 32(1): 95-99.

Parlak M, Blanco-Canqui H, 2015. Soil losses due to potato harvesting: a case study in western Turkey. Soil Use Manage. 31(4): 525-527.

Parlak M, Çiçek G, Blanco-Canqui H, 2018. Celery harvesting causes losses of soil: a case study in Turkey. Soil Tillage Res.180: 204-209.

Parlak M, Everest T, Ruis SJ, Blanco H, 2020. Impact of urbanization on soil loss: a case study from sod production. Environ. Monit. Assess. 192: 588.

Parlak M, Karaca S, Türkmen N, 2008. The cost of soil lost caused by sugar beet harvest: a case study for Turkey. J. Agric. Sci. 14 (3): 284-287.

Parlak M, Palta Ç, Yokuş S, Blanco-Canqui H, Çarkacı DA, 2016. Soil losses due to carrot harvesting in south central Turkey. Catena 140: 24-30.

Poesen JWA, Verstraeten G, Soenens R, Seynaeve L, 2001. Soil losses due to harvesting of chicory roots and sugar beet: an underrated geomorphic process? Catena 43: 35-47.

Pozza LE, Field DJ, 2020. The science of soil security and food security. Soil Security 1: 100002.

Ruysschaert G, Poesen J, Verstraeten G, Govers G, 2004. Soil loss due to crop harvesting: significance and determining factors. Prog. Phys. Geog. 28: 467-501.

SAS Institute Inc, 2018. SAS/Entreprise Guide Version 9.4.

Schertz DL, Nearing MA, 2002. Erosion tolerance/soil loss tolerances. (ed.Lal R), Encyclopedia of Soil Science. Marcel Dekker Inc. New York, USA. pp.448-451.

Stockmann U, Minasny B, McBratney AB, 2014. How fast does soil grow? Geoderma 216: 48-61.

Topp GC, Ferre PA, 2002. Water content. Methods of Soil Analysis. Part 4, Physical Methods(ed. Dane JH, Topp GC), SSSA, Book Series No: 5, Madison, pp. 417-545.

TÜİK, 2021. Türkiye İstatistik Kurumu. Tarımsal veriler. (Erişim tarihi: 22 Mart 2021) http://www.tuik.gov.tr

Yu H, Li Y, Zhou N, Chapell A, Li X, Poesen J, 2016. Soil nutrient loss due to tuber crop harvesting and its environmental impact in the North China Plain. J. Integr. Agr. 15(7): 1612-1624. 